\title{
Comparative Study on the Position of Shunt Active Power Filters in 25 kV AC Railway Systems
}

\author{
Haneol Park, Joongho Song ${ }^{1}$ and Wada M. Hosny ${ }^{2}$ \\ Department of New \& Renewable Energy Engineering, Kundong University, Andong, ${ }^{1}$ Department of Electrical Engineering \& Information \\ Technology, Seoul National University of Science and Technology, Seoul, Korea, ${ }^{2}$ Department of Electrical and Electronic Engineering, \\ University of East London, London, UK
}

\begin{abstract} positions of SAPF has been performed comprehensively.

Keywords

AC railway, Active power filter, Power quality, Static var compensator.
\end{abstract}

AC electrified railway systems show power quality problems such as harmonic current pollution, feeder voltage perturbation, and reactive power demand. These power quality problems have a bad effect on the AC railway system itself as well as other electric systems connected together. This paper investigates comparatively two configurations of a shunt active power filter (SAPF) for improving power quality in the AC railway systems. Different control algorithms corresponding to the installation position of the active power filter at the substation or at the sectioning post are proposed respectively. A comparative case study on the two

\section{Introduction}

The AC railway systems show typically poor power quality due to their inherent electrical load characteristics. The moving and non-linear load characteristics of the locomotives consume the large reactive power and produce high harmonic currents, so that the total power factor becomes adversely affected $[1,2]$. These power quality problems in the $\mathrm{AC}$ railway system have a detrimental effect on themselves as well as on the public grid [3]. The active power filter is widely used to maintain the power quality in the AC railway applications. The active power filter for the AC railway systems can be installed at two different positions as shown in Figure 1; one is at the substation (S/S) and the other at the sectioning post (SP). Many studies have been concentrated on the shunt active power filter (SAPF) installed at the S/S. The control algorithm and method for this case are relatively well established by the researches on the SAPF in the public power utility [4-6]. However, the AC railway system is a single-phase system so that the control algorithm for the SAPF in the system is significantly different from that which is used for the three-phase power utility [7]. There have been some studies carried out on the SAPF installed at the SP [8,9], but no comparative investigations regarding its location were $\mathrm{C}$ arried out.

In this paper, two SAPF configurations related to their locations are investigated. Each configuration is associated with a unique compensation characteristic.
Thus, they should be provided with different control algorithms and their performance should be compared for best outcome.

The compensation characteristics of two positions of SAPFs in the $25 \mathrm{kV}$ AC railway system are analyzed and their compensation performance is investigated comparatively in this paper. Also, the novel control algorithms based on the synchronous reference frame for each SAPF configuration are proposed. The effectiveness and the validity of the proposed control algorithms are demonstrated through the case study.

\section{Control of Shunt Active Power Filter Installed at Substation}

The $25 \mathrm{kV}$ AC electrified railway system can be considered as a lumped circuit [9]. In case of the overhead transmission line, the conductance in the parallel admittance of $\pi$-circuit can be neglected. Figure 2 shows the single-phase feeder line with the series resistance, the series inductance, and the parallel capacitance. In addition, the feeder line consists of three $10 \mathrm{~km}$-long $\pi$-sections, and the S/S transformer is described as an AC voltage source with internal impedance. It is shown in Figure 1 that the SAPF is basically composed of an inverter circuit, an L filter to suppress switching harmonics, and a DC-link capacitor. The locomotive is represented by a SCR bridgeconverter which generates the harmonic currents and the reactive power demand. 
Figure 3 shows the AC railway system with the SAPF provided at the $S / S$. The load current flowing into the locomotive, the SAPF current, and the DC-link voltage are measured for the controller input signals. Hysteresis control method is employed for the current control of the SAPF.

In this compensation system, in order to look into the relationship between the locomotive voltage and the reactive power compensation, an equivalent circuit can be described at the fundamental frequency as shown in Figure 4.

For the sake of simplicity, the source impedance and the parallel capacitance of line impedance are not considered. By defining $\mathbf{V}_{\mathrm{L}}=V_{L}+j 0$ as the reference phasor, the voltage drop across the feeder line is calculated as [10]

$$
\begin{aligned}
& \Delta \mathrm{V}=(R+j X) \mathrm{I}_{\mathrm{L}} \\
& =\frac{R P_{L}+X Q_{L}}{V_{L}}+j \frac{X P_{L}-R Q_{L}}{V_{L}}=\Delta V_{R}+j \Delta V_{X}
\end{aligned}
$$

where, the bold denotes phasor, and $V_{L^{\prime}} R, X, P_{L^{\prime}}$ and $Q_{L}$ mean the load voltage, the resistance of feeder line, the reactance, the active power of the load, and the reactive power, respectively. From (1), the phasor diagram of the feeding system without compensation can be depicted as shown in Figure 5.

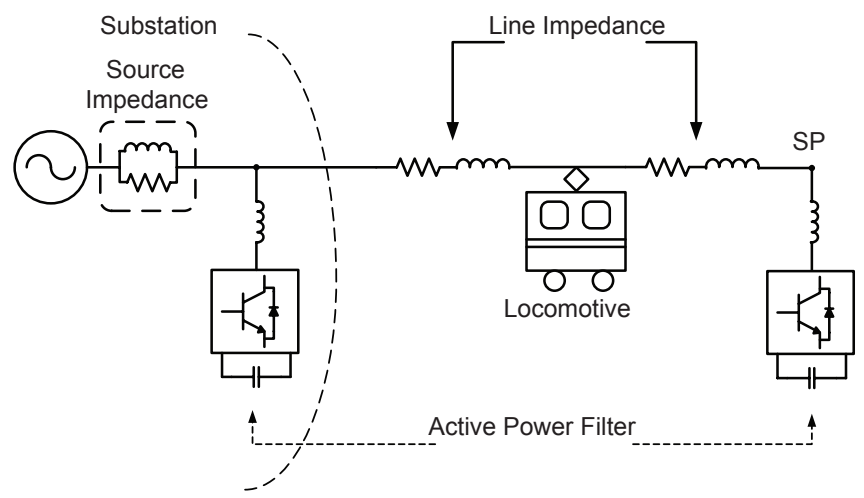

Figure 1: Two available installation positions of SAPF in AC railway systems.

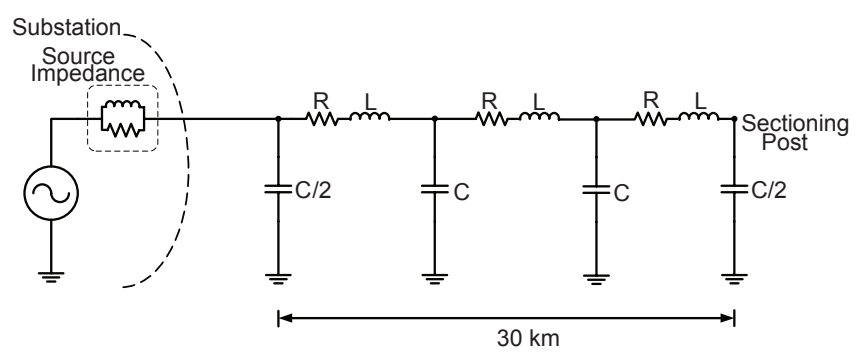

Figure 2: Modeling of the feeder line.
Using the phasor diagram, the square of source voltage magnitude is derived as

$\mathrm{V}_{S}=\mathrm{V}_{L}+\Delta \mathrm{V}=\mathrm{V}_{L}+\left(\Delta \mathrm{V}_{R}+j \Delta \mathrm{V}_{\mathrm{X}}\right)$

$\left|\mathrm{V}_{\mathrm{S}}\right|^{2}=V_{L}^{2}+|\Delta \mathrm{V}|^{2}+2\left(R P_{L}+X Q_{L}\right)$

If the SAPF is an ideal compensator and $Q_{S A P F}=-Q_{L}$ is satisfied, the reactive power supplied from the source becomes zero and (3) can be rewritten as

$$
\left|\mathrm{V}_{\mathbf{S}}\right|^{2}=\mathrm{V}_{\mathrm{L}}^{2}+|\Delta \mathrm{V}|^{2}+2\left[R P_{L}-X Q_{S A P F}\right]
$$

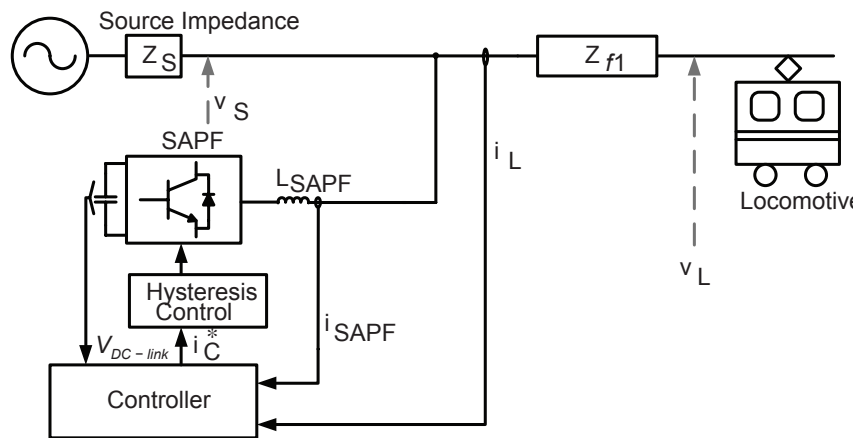

Figure 3: System configuration with SAPF installed at the S/S.

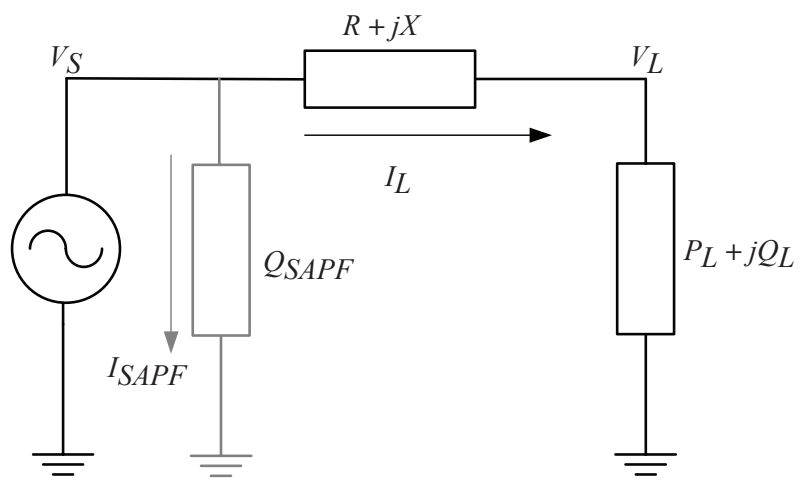

Figure 4: Equivalent circuit of AC railway network with SAPF installed at the S/S.

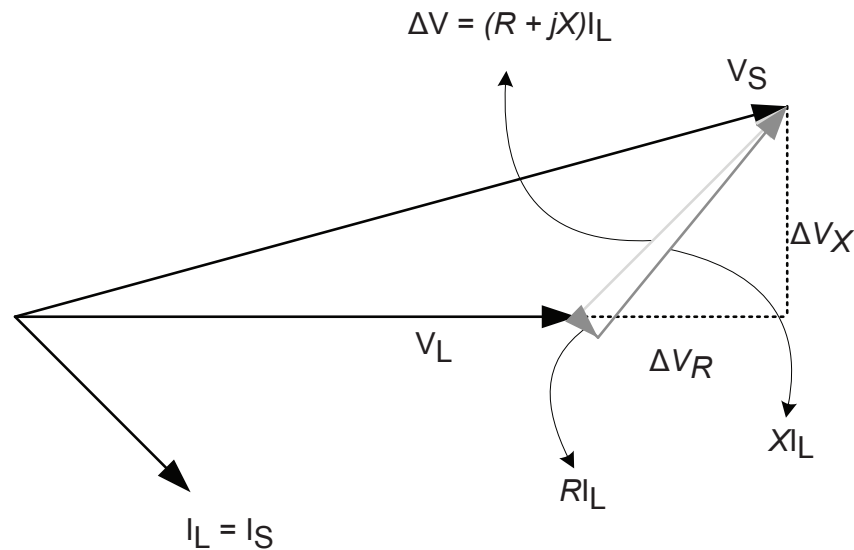

Figure 5: Phasor diagram with no compensation. 
Since the locomotive consumes the inductive reactive power, the value of $Q_{S A P F}$ is negative and the value of $|\Delta \mathrm{V}|^{2}+2\left[R P_{L}-X Q_{S A P F}\right]$ is always positive, not zero. The load voltage is not equal to the source voltage even when any compensation is taken. It is known that even though the unity power factor is achieved with the help of the SAPF, the magnitude of the source and load voltage cannot be the same. When the SAPF is installed at the $\mathrm{S} / \mathrm{S}$, the associated phasor diagram is shown in Figure 6.

When the SAPF is installed at the S/S, it is possible that the harmonic currents are effectively compensated by measuring the load current directly. The control objectives of the SAPF installed at the $\mathrm{S} / \mathrm{S}$ are to compensate the harmonic currents and reactive power demand for improving the input power factor.

\subsection{Harmonic Compensation}

The single-phase voltage and current signals can be handled on the stationary reference frame by assuming the imaginary values $90^{\circ}$ phase-shifted. The imaginary value can be calculated from the practical value through the various methods such as the Transport Delay, the Hilbert Transform, the Inverse-park Transform, and the Adaptive Notch Filter [11]. On the basis that the Inversepark Transform and the Adaptive Notch Filter are reported to be relatively superior to the other methods, the Inverse-park Transform is applied in this paper [12]. The $\alpha-\beta$ axis values of source voltage and load current in Figure 3 can be expressed as

$$
\begin{aligned}
& v_{S}(t) \triangleq v_{S \alpha}=V_{S} \cos \omega t+\sum_{n=3,5,7 \ldots}^{\infty} V_{S}(n) \cos n \omega t \\
& i_{L}(t) \triangleq i_{L \alpha}=I_{L} \cos (\omega t-\phi)+\sum_{n=3,5, \ldots \ldots}^{\infty} I_{L}(n) \cos \left(n \omega t-\phi_{n}\right) \\
& v_{S I}(t) \triangleq v_{S \beta}=V_{S} \sin \omega t+\sum_{n=3,5,7 \ldots}^{\infty} V_{S}(n) \sin n \omega t \\
& i_{L I}(t) \triangleq i_{L \beta}=I_{L} \sin (\omega t-\phi)+\sum_{n=3,5,7 \ldots}^{\infty} I_{L}(n) \sin \left(n \omega t-\phi_{n}\right)
\end{aligned}
$$

where, $V_{S^{\prime}} I_{L^{\prime}}$ and $n$ denote the maximum value of source voltage, the maximum value of load current, and the harmonic order, respectively. The $\alpha$-axis value is measured from the system and the $\beta$-axis value is calculated from the measured $\alpha$-axis value. From (5) to (8), it is possible that the source voltage and the load current vectors can be assumed and expressed on the stationary reference frame coordination as shown in Figure 7.

The voltage and current vectors in Figure 7 can be projected onto the synchronous reference frame rotating

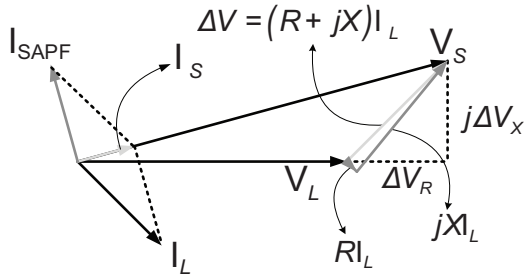

Figure 6: Phasor diagram with SAPF installed at the S/S.

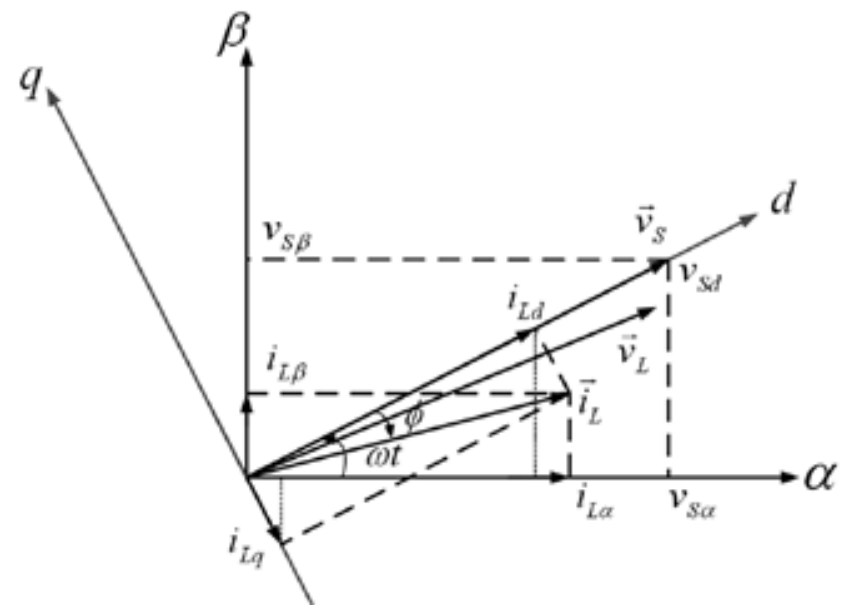

Figure 7: Voltage and current vector representation.

at the source frequency. The corresponding $d-q$ axis values of the load current are derived as

$\left[\begin{array}{l}i_{L d} \\ i_{L q}\end{array}\right]=T\left[\begin{array}{l}i_{L \alpha} \\ i_{L \beta}\end{array}\right]=\left[\begin{array}{cc}\cos \omega t & \sin \omega t \\ -\sin \omega t & \cos \omega t\end{array}\right]\left[\begin{array}{l}i_{L \alpha} \\ i_{L \beta}\end{array}\right]$

$=\left[\begin{array}{c}I_{L} \cos \phi+\sum_{n=3,5,7 \ldots}^{\infty} I_{L}(n) \cos \left[(n-1) \omega t-\phi_{n}\right] \\ -I_{L} \sin \phi+\sum_{n=3,5,7 \ldots}^{\infty} I_{L}(n) \sin \left[(n-1) \omega t-\phi_{n}\right]\end{array}\right]$

$=\left[\begin{array}{l}\bar{i}_{L d}+\tilde{i}_{L d} \\ \bar{i}_{L q}+\tilde{i}_{L q}\end{array}\right]$

where, the upper bar and the upper tilde means the DC value and the AC value of $d-q$ axis. It is known that the load current has both the fundamental and harmonic components. The $\mathrm{AC}$ value depends on the harmonic contents of load current. The DC value represents the fundamental load current and is easily obtained using the low pass filters (LPF) without any phase-shifting. When the $d-q$ axis DC values are subtracted from the $d-q$ axis load currents, only the $d-q$ axis AC values to be compensated remain. These components are provided as the current reference for the harmonic compensation to the controller. The harmonic compensation performance is illustrated in Figure 8. It is seen that the input current becomes perfectly sinusoidal after the harmonic compensation starts. 


\subsection{Reactive Power Compensation}

If the harmonic currents have already been compensated by the SAPF installed at the S/S and the $d$-axis is aligned on the source voltage vector as shown in Figure 7, the source voltage and current are sinusoidal, and expressed as

$$
\begin{aligned}
& {\left[\begin{array}{l}
i_{S d} \\
i_{S q}
\end{array}\right]=\left[\begin{array}{l}
\bar{i}_{L d} \\
\bar{i}_{L q}
\end{array}\right]=\left[\begin{array}{c}
I_{S} \cos \phi \\
-I_{S} \sin \phi
\end{array}\right]} \\
& {\left[\begin{array}{c}
v_{S d} \\
v_{S q}
\end{array}\right]=\left[\begin{array}{c}
\bar{v}_{S d} \\
\bar{v}_{S q}
\end{array}\right]=\left[\begin{array}{c}
V_{S} \\
0
\end{array}\right]}
\end{aligned}
$$

where, $I_{S}$ denotes the magnitude of source current. The source voltage and current vector are represented by the $d-q$ axis components on the synchronous reference frame as follows

$$
\begin{aligned}
& \vec{v}_{S}=v_{S d}+j v_{S q} \\
& \vec{i}_{S}=i_{S d}+j i_{S q}
\end{aligned}
$$

From (12) and (13), the following equation can be considered.

$\vec{v}_{S} \cdot \vec{i}_{S}^{*}=\left(v_{S d} i_{S d}+v_{S q} i_{S q}\right)+j\left(v_{S q} i_{S d}-v_{S d} i_{S q}\right)$

By substituting (10) and (11), (14) is expressed as follows

$$
\vec{v}_{S} \cdot \vec{i}_{S}^{*}=V_{S} I_{S} \cos \phi+j V_{S} I_{S} \sin \phi
$$$$
=P_{d q}+j Q_{d q}
$$

Using (15), the single-phase instantaneous power can be represented as follows

$$
\begin{aligned}
& p(t)=\frac{1}{2} V_{S} I_{S} \cos \phi[1+\cos (2 \omega t)]+\frac{1}{2} V_{S} I_{S} \sin \phi \sin (2 \omega t) \\
& =\frac{1}{2} P_{d q}[1+\cos (2 \omega t)]+\frac{1}{2} Q_{d q} \sin (2 \omega t)
\end{aligned}
$$



(a)

$$
=\frac{1}{2} v_{S d} i_{S d}[1+\cos (2 \omega t)]-\frac{1}{2} v_{S d} i_{S q} \sin (2 \omega t)
$$

The first term of (16) is defined as the single-phase instantaneous active power and the second term is defined as the single-phase instantaneous reactive power [13]. It is known from (16) that when the source voltage is constant, the single-phase instantaneous active power depends on the $d$-axis current and the single-phase instantaneous reactive power relies solely on the $q$-axis current. Therefore, the SAPF installed at the S/S can compensate the reactive power demand by controlling the $q$-axis value of source current to be zero instead of controlling the instantaneous reactive power.

Figure 9 shows the overall control scheme of the SAPF installed at the S/S. The $d-q$ transform block includes both the single-phase to two-phase transformation and the transformation into the synchronous reference frame. The reference of $q$-axis source current in the reactive power compensation loop is set at zero. The error between the reference and the actual value of the $q$-axis source current enters the PI controller, and then it is added to the $q$-axis current reference for the harmonic compensation because the $q$-axis source current determines the instantaneous reactive power. No additional current sensor to measure the source current is required. Among the outputs of inverse $d-q$ transform block, only the $\alpha$-axis value becomes the current reference for the hysteresis controller. The DC-link voltage regulator plays a role in compensating the power losses of the SAPF as well as the voltage regulation.

Figure 8 shows the performance of the harmonic and the reactive power compensation when the SAPF is installed at the S/S with the proposed control strategy. It is shown that when the harmonic and the reactive power compensation are provided, there exists no phase deviation between the source voltage and the source current, whereas the result with only the harmonic compensation shows a certain phase shift.

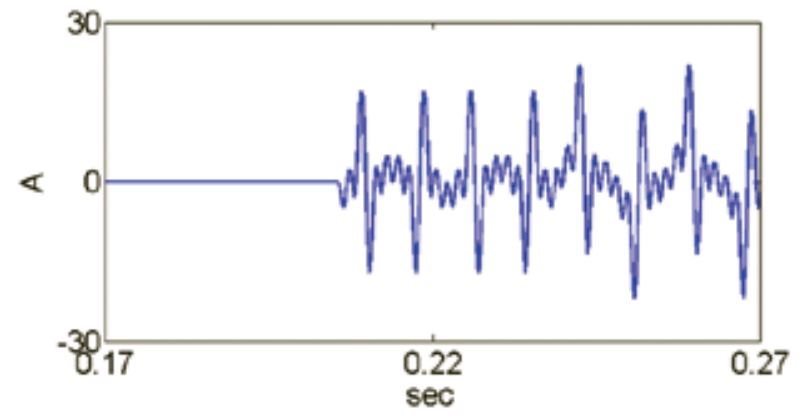

(b)

Figure 8: Harmonic compensation (a) Substation voltage and current; (b) Compensation current. 


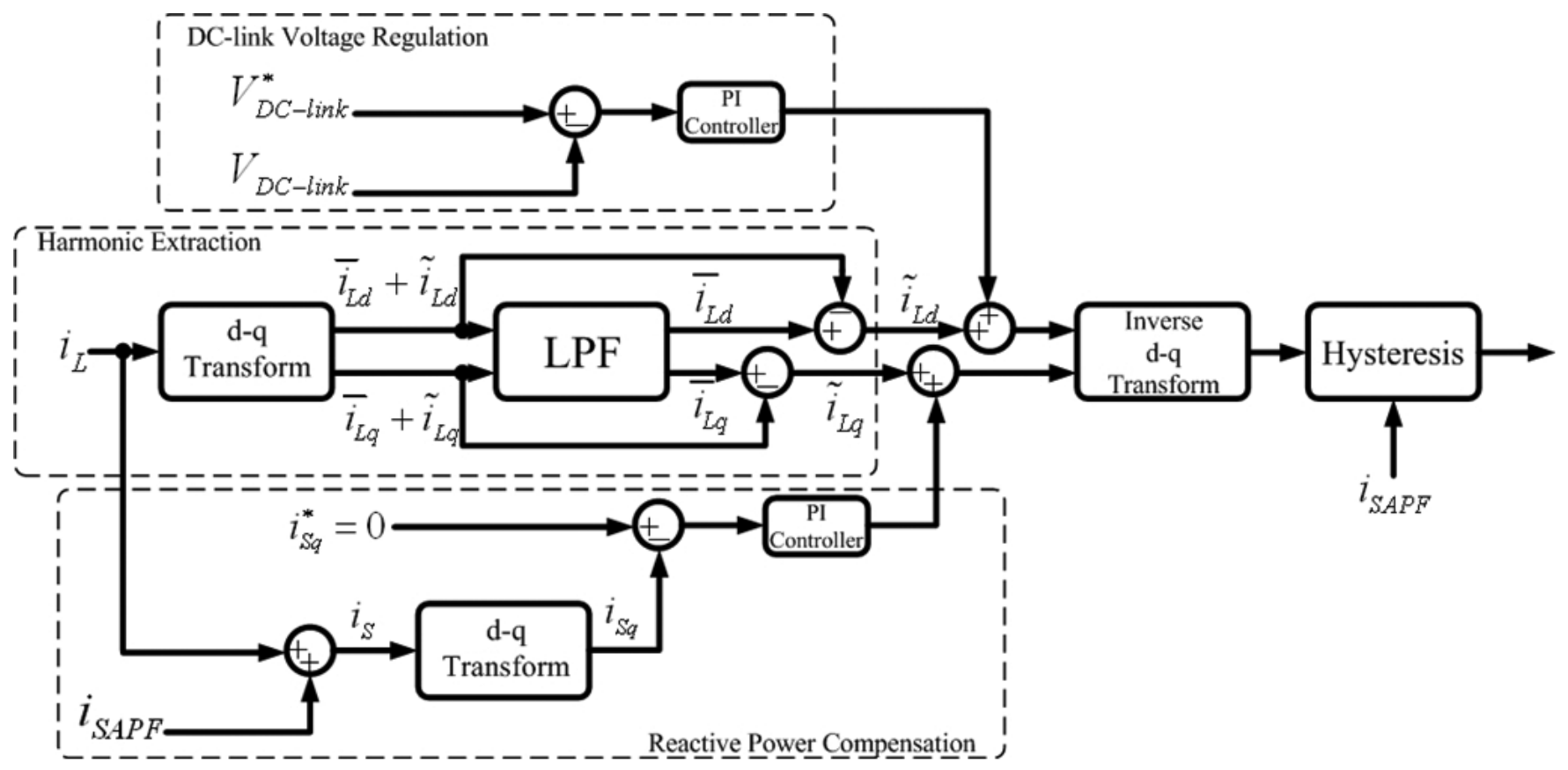

Figure 9: Overall control scheme of SAPF installed at the S/S.

\section{Control of Shunt Active Power Filter Installed at Sectioning Post}

Figure 10 shows another AC railway system with the SAPF installed at the SP. In this case, the load current cannot be measured as a feedback signal in a sense of practice. Therefore, the SP voltage should be used as the feedback signal instead of the harmonic load current.

Similarly, with Figure 4, the equivalent circuit of AC railway system with the SAPF installed at the SP is represented as shown in Figure 11.

When the SAPF is provided at the SP, the voltage drop across the feeder line is derived as

$$
\begin{aligned}
& \Delta \mathrm{V}=(R+j X) \mathrm{I}_{\mathrm{S}}=(R+j X)\left(\mathrm{I}_{\mathrm{L}}+\mathrm{I}_{\mathrm{SAPF}}\right) \\
& =\frac{R P_{L}+X\left(Q_{L}+Q_{S A P F}\right)}{V_{L}}+j \frac{X P_{L}-R\left(Q_{L}+Q_{S A P F}\right)}{V_{L}} \\
& =\Delta V_{R}+\frac{X Q_{S A P F}}{V_{L}}+j\left(\Delta V_{X}-\frac{R Q_{S A P F}}{V_{L}}\right)
\end{aligned}
$$

From (17), the square of source voltage magnitude is expressed as

$$
\left|\mathrm{V}_{\mathrm{S}}\right|^{2}=\left[V_{L}+\Delta V_{R}+\frac{X Q_{S A P F}}{V_{L}}\right]^{2}+\left[\Delta V_{X}-\frac{R Q_{S A P F}}{V_{L}}\right]^{2}
$$

It is known from (18) that the SAPF installed at the SP can compensate the voltage drop by generating the reactive



Figure 10: System configuration with SAPF installed at the SP.

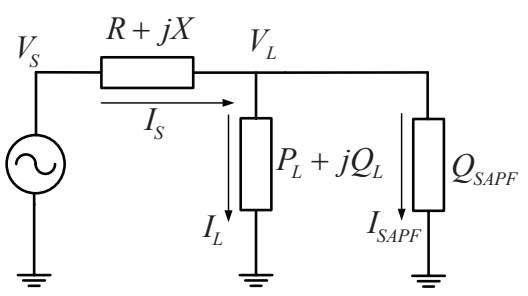

Figure 11: Equivalent circuit with SAPF installed at the SP.

power to maintain $\left|\mathrm{V}_{\mathrm{S}}\right|=V_{L}$. In practice, the reactive power to compensate the voltage drop is determined automatically by a closed-loop control [10]. When the $\mathrm{SAPF}$ is provided at the SP, the associate phasor diagram of the feeding system is shown in Figure 12.

In case of the SAPF installed at the SP, it is natural to compensate the voltage drop and the current 
harmonics by sensing the SP voltage. Therefore, the control objectives of the SAPF installed at the SP are to compensate the voltage drop and harmonic currents. In the AC railway system with the SAPF installed at the SP, an equivalent circuit showing the harmonics flow can be modeled as shown in Figure 13.

\subsection{Harmonic Compensation}

Figure 13 shows that the SP harmonic voltage is influenced by the harmonic currents flowing from the locomotive. The harmonic load current, which cannot be measured at the SAPF installed at the SP, can be obtained by the SP voltage as follows

$$
\begin{aligned}
& i_{L}(h)=-\frac{Z_{s}(h)+Z_{f 1}(h)+Z_{f 2}(h)+Z_{S A P F}(h)}{\left(Z_{s}(h)+Z_{f 1}(h)\right) Z_{S A P F}(h)} v_{S P}(h) \\
& =-\frac{Z_{1}(h)+Z_{2}(h)}{Z_{1}(h) Z_{S A P F}(h)} v_{S P}(h) \\
& =-Y_{e q}(h) v_{S P}(h)
\end{aligned}
$$

where, $h$ indicates the harmonic order, and $Z_{S}(h)$, $Z_{f 1}(h), Z_{f 2}(h)$, and $Z_{\text {SAPF }}(h)$ denote the source impedance, the feeder line impedance between the source and locomotive, between the locomotive and SP, and the SAPF equivalent impedance at the harmonic frequency, respectively. Figure 14 depicts how the equivalent admittance between the harmonic load current and the SP harmonic voltage changes as the locomotive runs along the feeder line. It is seen that the equivalent admittance is nearly constant with respect to changing the locomotive position. Therefore, the harmonic load current can be estimated by the measured SP harmonic voltage, considering the equivalent admittance.

When the SP voltage is transformed into the synchronous reference frame with the SP voltage frequency, the corresponding $d-q$ axis values of the SP voltage are expressed as

$\left[\begin{array}{c}v_{S P d} \\ v_{S P q}\end{array}\right]=\left[\begin{array}{l}\bar{v}_{S P d}+\tilde{v}_{S P d} \\ \bar{v}_{S P q}+\tilde{v}_{S P q}\end{array}\right]$

where, the $d-q$ axis values of the SP voltage with the upper bar denotes the fundamental SP voltage. The extraction of harmonic SP voltage is similar to the harmonic currents extraction method by the LPF. Using the extracted $d-q$ axis harmonic SP voltage, (19) can be expressed on the synchronous reference frame as follows

$\left[\begin{array}{l}\tilde{i}_{L d} \\ \tilde{i}_{L q}\end{array}\right] \approx\left[\begin{array}{l}-Y_{e q}(h) \tilde{v}_{S P d} \\ -Y_{e q}(h) \tilde{v}_{S P q}\end{array}\right]$



Figure 12: Phasor diagram with SAPF installed at the SP.

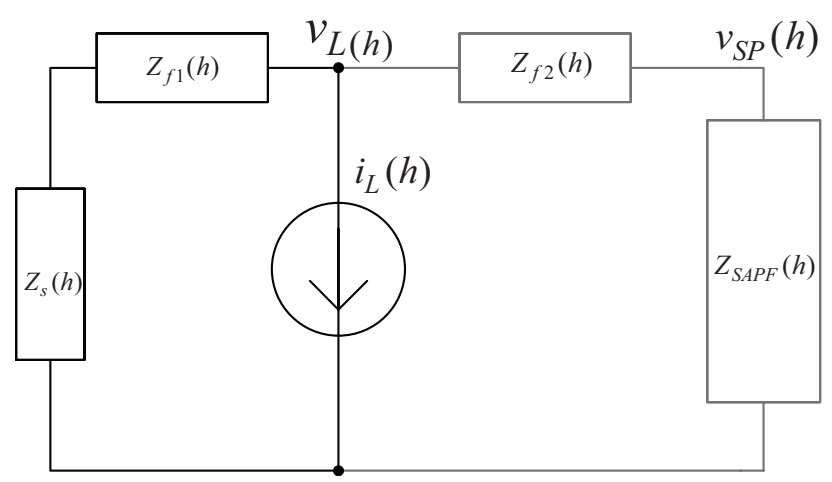

Figure 13: Harmonics flow from load current.

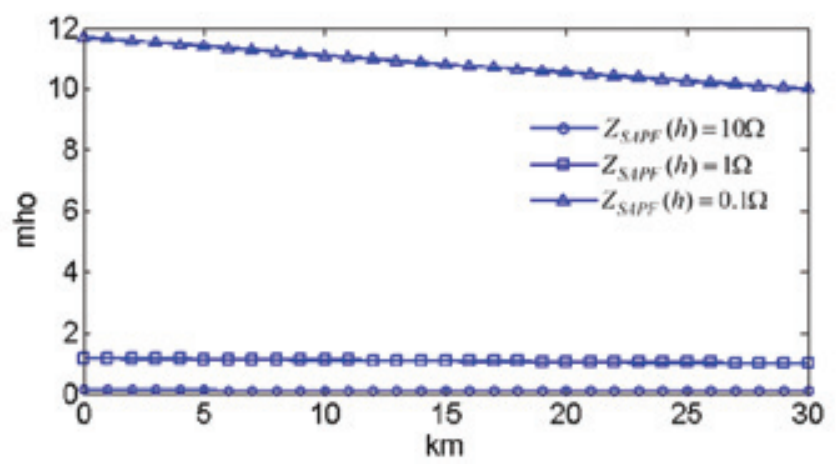

Figure 14: Equivalent admittance against locomotive position.

The approximate equivalent impedance for the case study is determined at $25 \Omega$ using the trial-and-error method in this paper. The DC-link voltage regulator is added on the $d$-axis control block in the same manner as the compensation system with the SAPF installed at the S/S. Figure 15 shows the harmonic extraction results obtained from the harmonic SP voltage. It is shown that there is slight deviation between the directly measured harmonic load current and the indirectly estimated harmonic load current from the harmonic $\mathrm{SP}$ voltage. Furthermore, the estimation accuracy varies with the locomotive positions: The nearer the locomotive approaches the SP, the better the estimation performance is. 


\subsection{Reactive Power Compensation}

Since the $d-q$ axis rotates at the same angular speed as the SP voltage vector, the $d$-axis value of the SP voltage contains the harmonic components as well as the fundamental component of the SP voltage. Figure 16 shows the overall control scheme of the SAPF installed at the SP.

It is shown in the reactive power compensation loop that the error between the actual DC value and the voltage reference of the $d$-axis SP voltage enters the PI controller. This voltage drop can be compensated by controlling the reactive power of the SAPF installed at the SP. Therefore, the control output of PI controller is added on the $q$-axis current reference for the harmonic compensation as shown in Figure 16. The $d$-axis SP voltage reference is set at the nominal value of the $A C$ electrified railway system in order to support the locomotive terminal voltage above the lower limit under the full load.

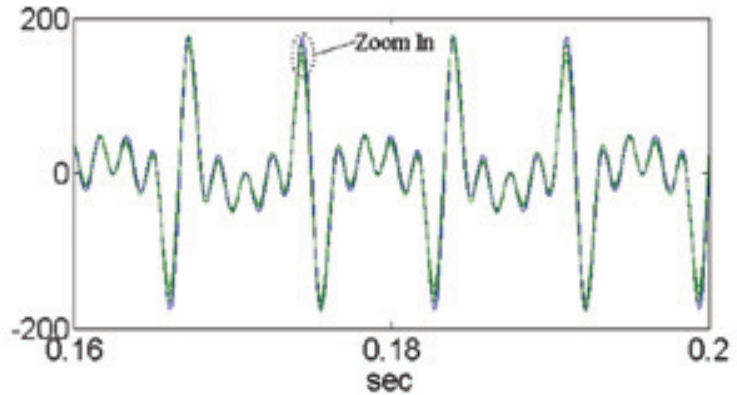

(a)

\section{Case Study}

Two SAPF configurations with the corresponding control algorithms are simulated in the $25 \mathrm{kV}$ AC railway system by Matlab/SimPowerSystems platform. The system parameters for the simulation are shown in Table 1 (Appendix) [14].

When the locomotive is $20 \mathrm{~km}$ away from the $\mathrm{S} / \mathrm{S}$, the corresponding simulation results are plotted in Figure 17. Figure 17a-d shows the voltage and current waveforms of the railway system with no compensation facility.

Table 1: System parameters for simulation

\begin{tabular}{lc}
\hline Source voltage & $25 \mathrm{kV}, 60 \mathrm{~Hz}$ \\
\hline Filter inductor & $5 \mathrm{mH}$ \\
DC-link capacitor & $2500 \mathrm{uF}$ \\
Source impedance & $1000 \Omega, 27.1 \mathrm{mH}$ \\
Pi-section line resistance & $0.16 \Omega / \mathrm{km}$ \\
Pi-section line inductance & $1.4 \mathrm{mH} / \mathrm{km}$ \\
Pi-section line capacitance & $0.01 \mathrm{uF} / \mathrm{km}$ \\
\hline
\end{tabular}

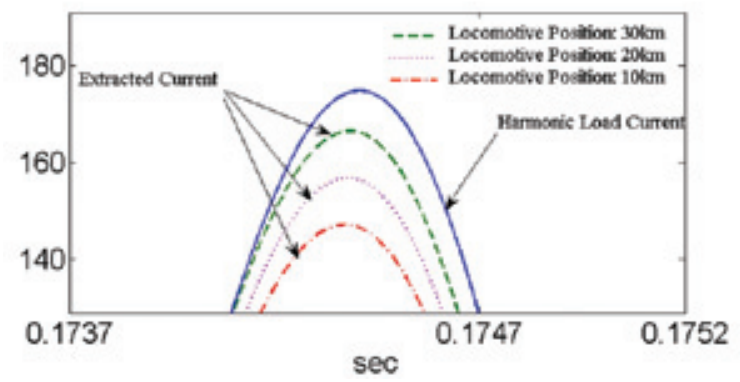

(b)

Figure 15: Harmonic load current extraction using the SP voltage (a) Actual and extracted current waveforms; (b) Waveforms zoomed in.



Figure 16: Overall control scheme of SAPF installed at the SP. 


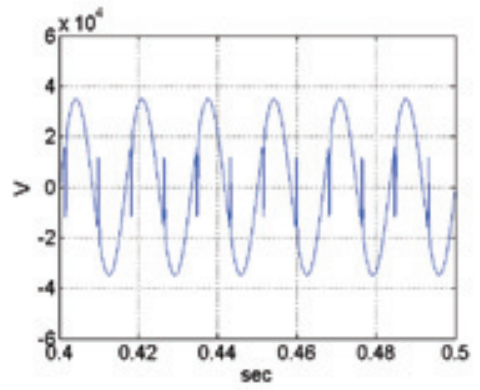

(a)

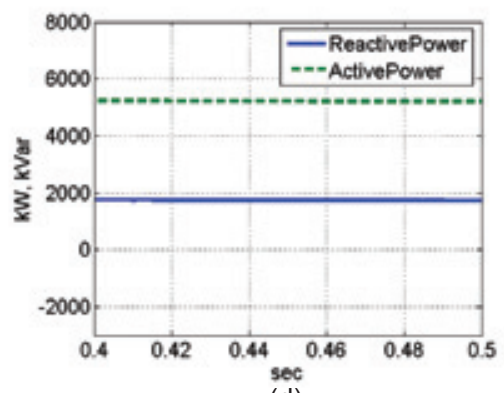

(d)

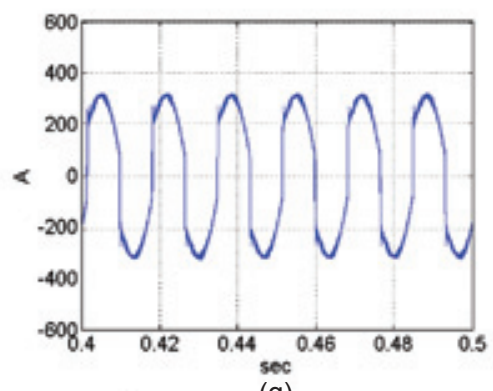

(g)

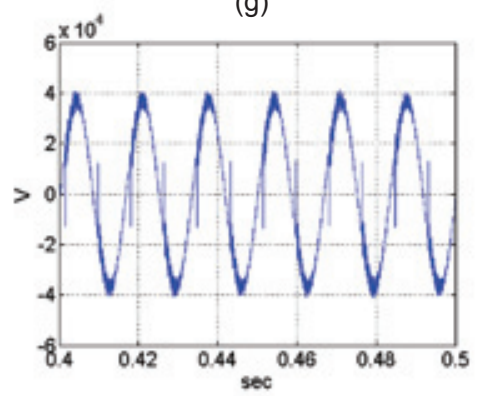

(j)

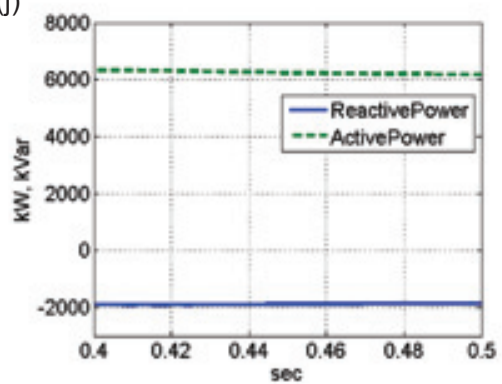

(m)

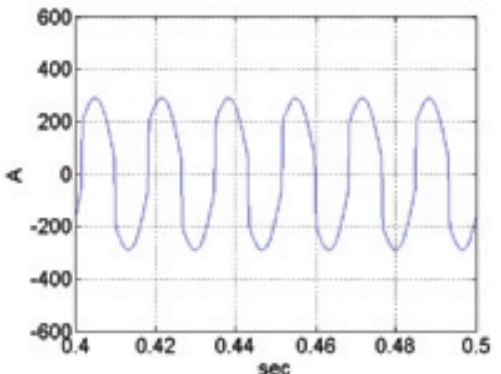

(b)

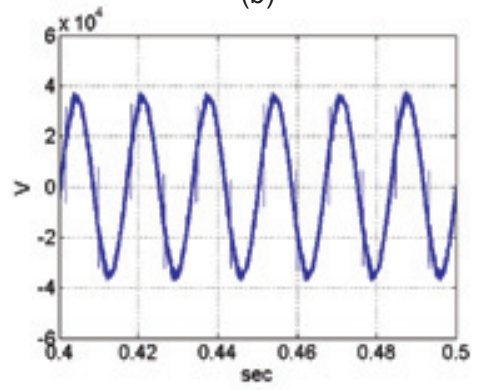

(e)

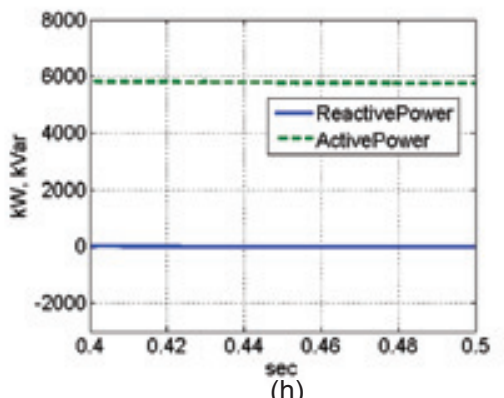

(h)

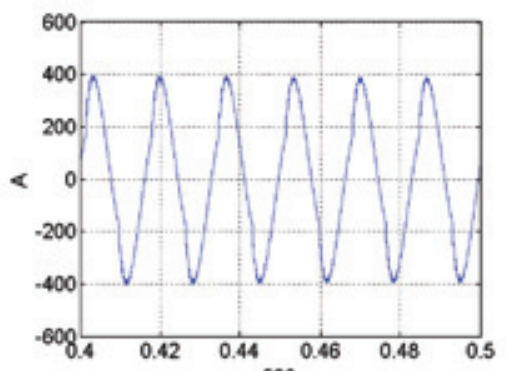

(k)

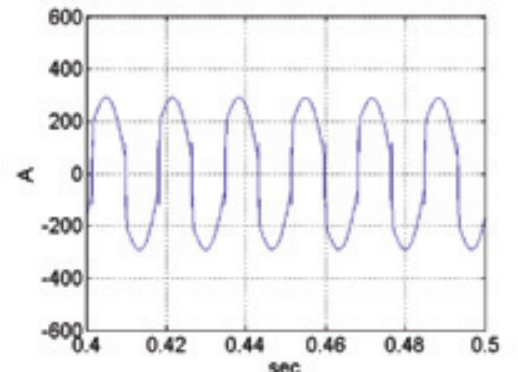

(c)

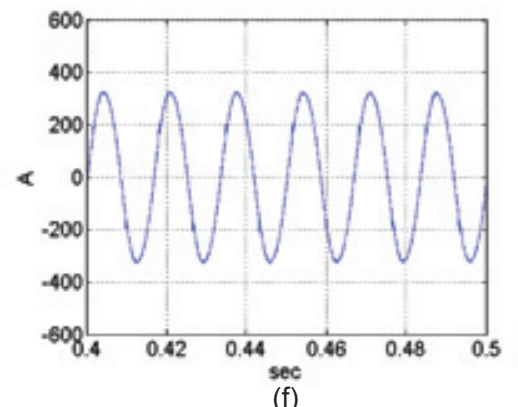

(f)
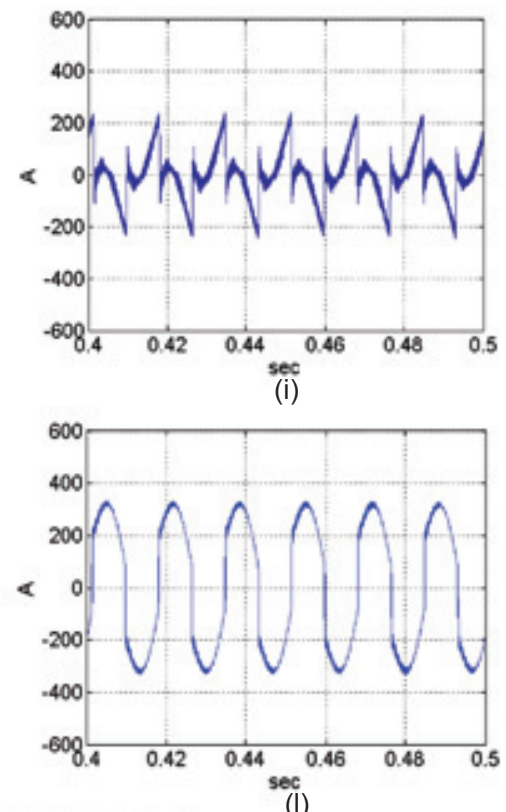

(I)

Figure 17: Simulation results when locomotive is 20km away from the S/S; (a) Source voltage (without SAPF); (b) Source current (without SAPF); (c) Load current (without SAPF); (d) Active and reactive power supplied from source (without SAPF); (e) Source voltage (with SAPF at S/S); (f) Source current (with SAPF at S/S); (g) Load current (with SAPF at S/S); (h) Active and reactive power supplied from source (with SAPF at S/S); (i) SAPF current (with SAPF at S/S); (j) Source voltage (with SAPF at SP); (k) Source current (with SAPF at SP); (1) Load current (with SAPF at SP); (m) Active and reactive power supplied from source (with SAPF at SP); (n) SAPF current (with SAPF at SP). 
The waveform of the load current is distorted and is not sinusoidal due to the electrical non-linearity of the locomotive. As the SAPF is not provided, the source current is consequently distorted. In this case, the reactive power supplied from the source is about $1800 \mathrm{kVar}$. When the SAPF is installed at the S/S, the corresponding waveforms are shown in Figure 17e-i. It can be seen that the source current has very little harmonic currents because the SAPF compensates the harmonic currents effectively. In addition, the reactive power supplied from the source is nearly zero because the SAPF compensates the reactive power demand completely. On the other hand, when the SAPF is installed at the SP, the respective waveforms are illustrated in Figure 17j-n. The reactive power supplied from the source cannot be zero, being different from when the SAPF is installed at the S/S. Since the reactive power is used to compensate the voltage drop across the feeder line, the input power factor is not unity and shows a leading one.

Figure 18 shows the FFT results of the source current, and Tables 2 and 3 show the THD and the input power factor of each compensation case. It is seen that the input power factor and THD performances of each compensation method do not show a big difference according to the position of locomotive away from the S/S. It can be seen from Figure 18 that the source current has large amount of the harmonic contents when the SAPF is not provided. In this case, the THD of the source current is as big as about $21 \%$ and the power factor is poor. When the SAPF is installed at the S/S, the corresponding FFT result of source current shows the superiority of the SAPF control algorithm proposed to compensate the harmonic contents in the load current. As a result, it is seen that the power factor can be improved up to unity.

On the other hand, when the SAPF is installed at the $\mathrm{SP}$, the source current has harmonic components more reduced than the results without the SAPF, but shows higher THD and lower power factor than the SAPF installed at the S/S. Even so, THD results of the compensated source current are below $12 \%$ and power

Table 2: THD results

\begin{tabular}{lccc}
\hline & $10 \mathrm{~km}$ & $20 \mathrm{~km}$ & $30 \mathrm{~km}$ \\
\hline THD (without SAPF) & 21.1 & 21.2 & 20.9 \\
THD (with SAPF at S/S) & 3.4 & 3.4 & 3.5 \\
THD (with SAPF at SP) & 11.4 & 10.9 & 11.2 \\
\hline THD - Kindly expand???; SAPF - Shunt active power filter &
\end{tabular}

Table 3: Power factor

\begin{tabular}{lccc}
\hline & $10 \mathrm{~km}$ & $20 \mathrm{~km}$ & $30 \mathrm{~km}$ \\
\hline Power Factor (without SAPF) & 0.88 & 0.88 & 0.88 \\
Power Factor (with SAPF at S/S) & 0.99 & 0.99 & 0.99 \\
Power Factor (with SAPF at SP) & 0.99 & 0.97 & 0.97 \\
\hline SAPF - Shunt active power filter; SP - Kindly expand???,
\end{tabular}

factor is above 0.97. It is shown that the proposed SAPF control algorithm can properly compensate the harmonic currents and improve the input power factor even when the SAPF is installed at the SP.

Figure 19 shows the variation of the voltage reduction measured at the receiving terminal of the locomotive when the locomotive runs along the feeder line. It is known that the voltage reduction is proportional to the distance in which the locomotive is positioned away from the S/S. When the SAPF is not provided and the locomotive is positioned near the SP, the locomotive receives the feeder voltage lower than the nominal voltage by $2.7 \mathrm{kV}$. When the SAPF is installed at the S/S, the voltage drop at the locomotive is relatively reduced.

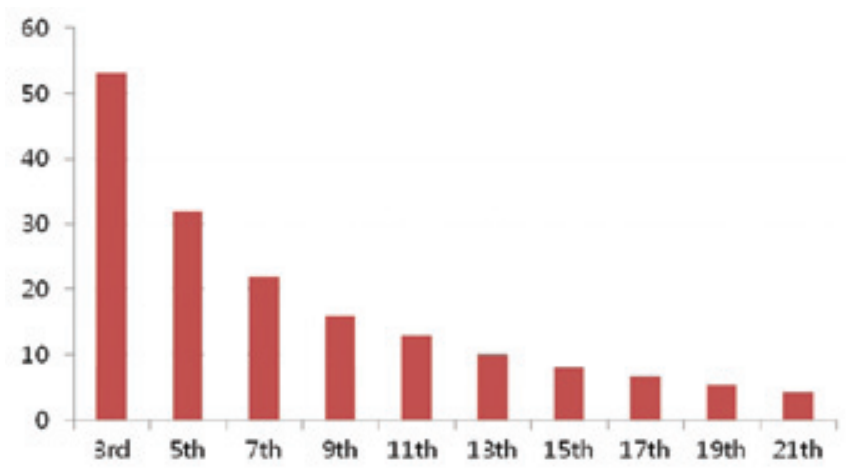

(a)

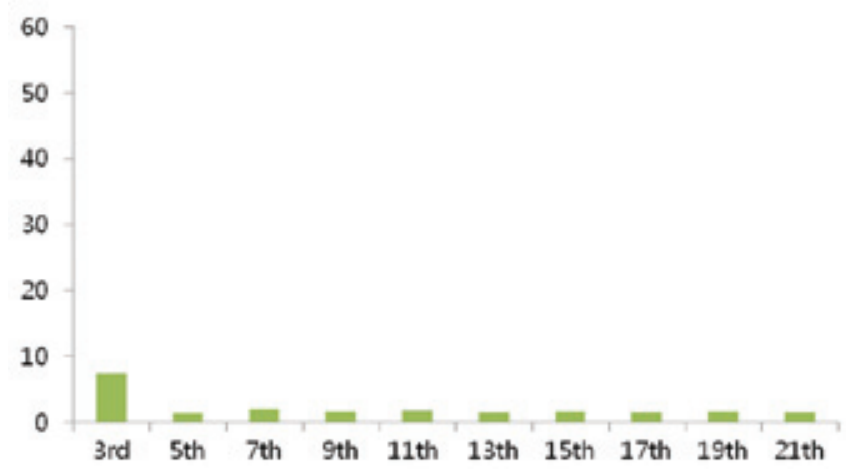

(b)



(c)

Figure 18: FFT results of source current (a) When SAPF is not provided; (b) When SAPF is installed at the S/S; (c) When SAPF is installed at the SP. 
It is seen in Figure $19 b$ that the farther the locomotive is away from the SAPF, the bigger the voltage reduction is. This value is above $1.5 \mathrm{kV}$, which is still high. However, when the SAPF is installed at the SP, the voltage drop at the locomotive is compensated relatively well. It is shown in Figure 19c that the voltage drop at the locomotive is nearly zero when the locomotive approaches the SP.

Figure 20 shows variation of the locomotive terminal voltage when the source voltage sag of $30 \%$ occurs from $0.4 \mathrm{~s}$ to $0.6 \mathrm{~s}$. When the SAPF is not provided, the respective locomotive voltage is below the lower limit voltage of the locomotive, $19 \mathrm{kV}$, which can cause the circuit breaker to be open. When the SAPF is installed at the $S / S$, the locomotive voltage is supported above the lower limit voltage. When the SAPF is installed at the SP, it is shown in Figure 20c that the voltage sag can be considerably compensated by the SAPF. Even though the locomotive voltage response shows a transient fluctuation, the influence of the voltage sag is relatively mitigated with the help of the SAPF installed at the SP.

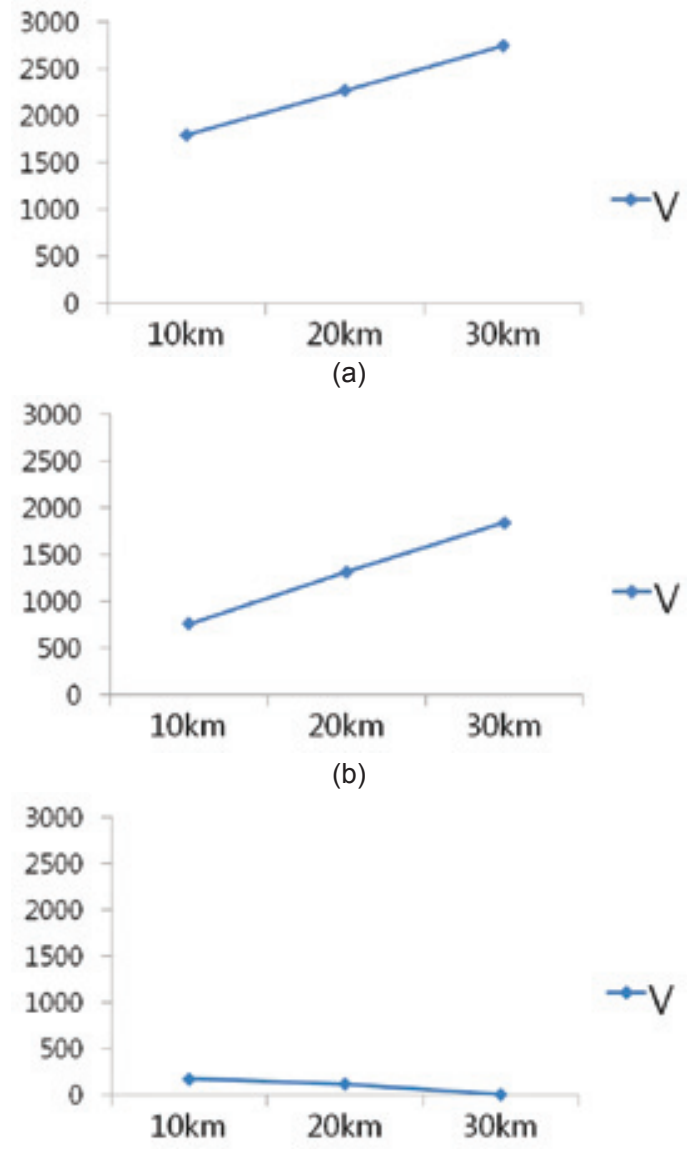

(c)

Figure 19: Voltage reduction of the receiving voltage of locomotive (a) When SAPF is not provided; (b) When SAPF is installed at the S/S; (c) When SAPF is installed at the SP.

\section{Conclusion}

This paper presents a comparative study on the SAPF applications to the AC railway systems and proposes a novel control algorithm based on the synchronous reference frame. The comparative study on two SAPF configurations is demonstrated through the case study. The results show that the proposed SAPF control algorithm properly compensates the power quality

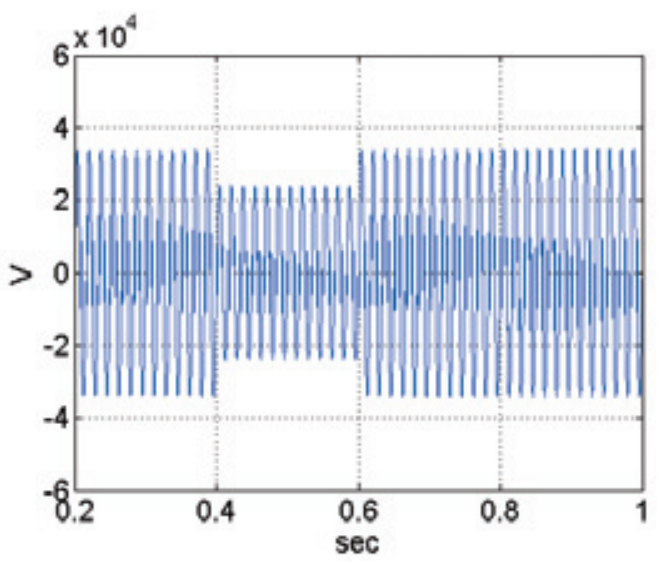

(a)

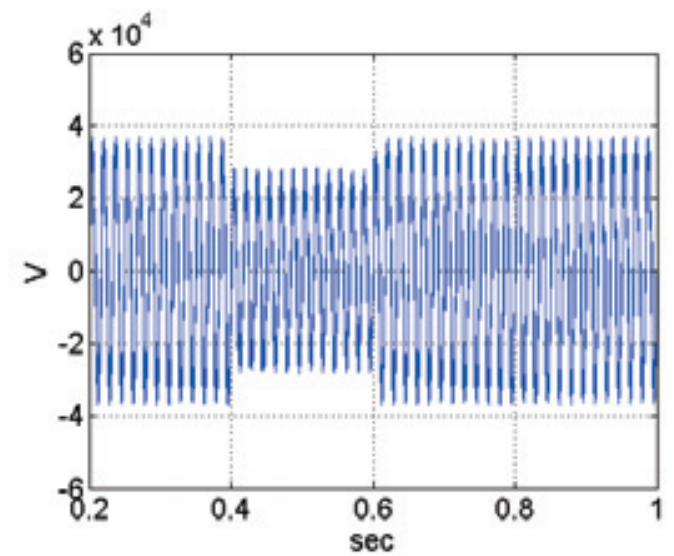

(b)

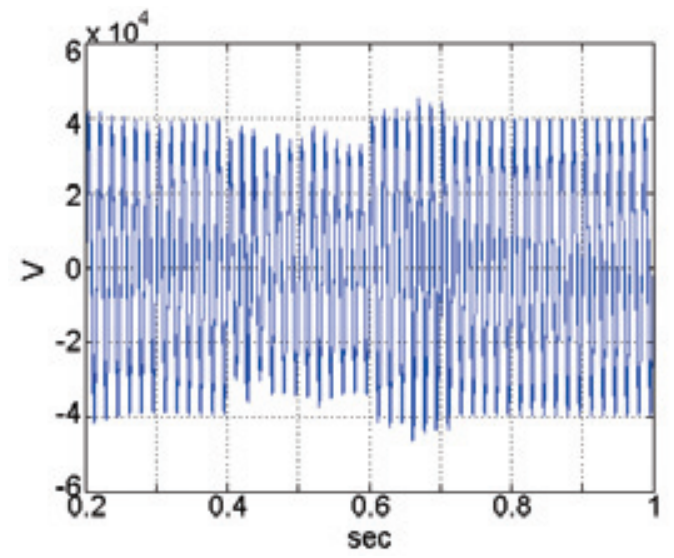

(c)

Figure 20: Locomotive voltage when voltage sag occurs (a) Without SAPF; (b) With SAPF installed at the S/S; (c) With SAPF installed at the SP. 
problems in the AC railway systems, such as the harmonic current pollution, the voltage perturbation, and the reactive power demand. When the SAPF is installed at the $S / S$, the performance to compensate the harmonic currents is vastly superior. Also, the reactive power demand can be completely compensated so that the input power factor is nearly unity. However, the voltage drop and the voltage sag cannot be fully compensated.

When on the other hand, the SAPF is installed at the $\mathrm{SP}$, the static voltage drop and voltage sag can be compensated effectively. However, because the control algorithm of SAPF installed at the SP is based on indirect harmonic currents extraction by sensing the SP voltage instead of the load current, the harmonic compensation performance is inferior to that of the SAPF installed at $\mathrm{S} / \mathrm{S}$. The two appropriate control structures of the SAPF have clearly different compensation characteristics. Therefore, the proper selection of the SAPF position and its control algorithm according to the compensation purposes should be considered carefully to apply the SAPF successfully to the AC railway applications.

\section{References}

1. L. Battistelli, D. Lauria, and D. Proto, "Two-phase controlled compensator for alternating-current quality improvement of electrified railway systems," IEE Trans. Electric Power Applications, Vol. 153, no. 2, pp. 177-83, 2006.

2. Z. Sun, X. Jiang, D. Zhu, and G. Zhang, "A novel power quality compensator topology for electrified railway," IEEE Trans. Power Electronics, Vol. 19, no. 4, pp. 1036-42, 2004.

3. W. Jinhao, X. Lei, L. Yuzhuo, L. Mengzan, P. Leilei, and L. Shuying, et al., "The interaction research between public grid and traction power supply system," in Proc. IEEE China Int. Conf. Electricity Distribution, pp. 1-8, 2008.

4. P. Salmeron, and S. Litran, "Improvement of the electric power quality using series active filter and shunt passive filter," IEEE Trans. Industrial Electronics, Vol. 25, no. 2, pp. 1058-67, 2010.

5. V. Corasaniti, M. Barbieri, P. Arnera, and M. Valla, "Hybrid active filter for reactive and harmonics compensation in a distribution network," IEEE Trans. Industrial Electronics, Vol. 56, no. 3, pp. 670-7, 2009.

6. A. Luo, Z. Shuai, W. Zhu, Z. Shen, and C. Tu, "Design and application of a hybrid active power filter with injection circuit," IET Trans. Electric Power Applications, Vol. 3, no. 1, pp. 54-64, 2010.

7. S. Mekhilef, M. Tarek, and N. Rahim, "Single-phase hybrid active power filter with adaptive notch filter for harmonic current estimation," IETE Journal of Research, Vol. 57, no. 1, pp. 20-8, 2011.

8. H. Akagi, "New trends in active filters for power conditioning," IEEE Trans. Industry Applications, Vol. 32, no. 6, pp. 1312-22, 1996.

9. P. Tan, P. Loh, and D. Holmes, "High-performance harmonic extraction algorithm for a $25 \mathrm{kV}$ traction power quality conditioner," IEE Trans. Electric Power Applications, Vol. 20, no. 2, pp. 1703-10, 2005.

10. E. Acha, V. Agelidis, O. Anaya-Lara, and T. Miller, "Power Electronic Control in Electrical Systems," Ch. 2., Oxford: Newnes; 2002. p. 45.

11. S. Silva, B. Lopes, B. Cardoso Filho, R. Campana, and W. Boventura, "Performance evaluation of PLL algorithms for single-phase grid-connected systems," in Proc. IEEE Annual. Conf. Industry Applications, pp. 2259-63, 2004.

12. R. Santos Filho, P. Sixas, P. Cortizo, and L. Torres, "Comparison of three single-phase PLL algorithms for UPS applications," IEEE Trans. Industrial Electronics, Vol. 55, no. 8, pp. 2923-32, 2008.

13. M. Saitou, N. Matsui, and T. Shimizu, "A control strategy of singlephase active filter using a novel d-q transformation," in Proc. IEEE Int. Conf. Industry Applications, pp. 1222-7, 2003.

14. P. Tan, P. Loh, and D. Holmes, "Optimal impedance termination of $25-\mathrm{kV}$ electrified railway systems for improved power quality," IEEE Trans. Power Delivery, Vol. 20, no. 2, pp. 1703-10, 2005.

\section{AUTHORS}

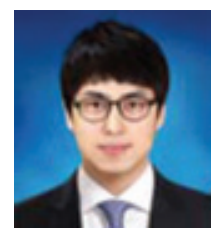

Haneol Park was born in Korea in 1980. He received B.S. and M.S. degrees in electrical engineering in 2006 and 2008, and PhD in railway electrical and signaling engineering in 2011 from Seoul National University of Science and Technology. He has been an Associate Professor in the department of New \& Renewable Energy Engineering at Kundong University, Korea. His primary research interests are renewable energy PCS, electrified railway systems, power quality, and power converters.

E-mail: haneol@kundong.ac.kr

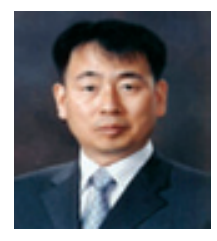

Joongho Song was born in Korea in 1957. He received B.S. and M.S. degrees in electrical engineering from Seoul National University in 1980 and 1982, and his $\mathrm{PhD}$ from KAIST, Korea, in 1993. He worked as an engineer for E-Hwa Electrical Co., Korea, from 1982 to 1985. From 1982 to 2002, he was with the Intelligent System Control Research Center, Korea Institute of
Science and Technology. He was a visiting scholar at the University of Wisconsin-Madison from 1995 to 1996. Since 2002, he has been an Associate Professor in the department of Electrical Engineering \& Information Technology at Seoul National University of Science and Technology, Korea. His primary research interests include switching converter, electric machine drives, and renewable energy technologies.

E-mail: joongho@seoultech.ac.kr

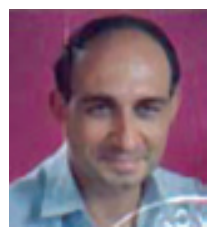

Wada M. Hosny was born in Egypt in 1950, received B.S. and M.S. degrees in electrical engineering from Military Technical College, Egypt, in 1972 and 1976, and his PhD from Cranfield University, UK, in 1981. He has been working as a Lecturer at Sheffield Hallam University, UK, a Principal Lecturer in the department of Electrical and Electronic Engineering at the University of East London, UK. He occupied Tokyo Power Engineering Company Chair, Japan, and was a visiting Professor in the University of Kentucky, USA. His primary research interests include electric power systems, electric drives, active power filters, and power converters.

E-mail:w.m.hosny@uel.ac.uk

\section{DOI: ***; Paper No. TR 401_11; Copyright @ 2012 by the IETE}

AQ 3: Please check the headings???

AQ 5: Kindly check

AQ 7: Plz confirm all figures and it's respective citation 